\title{
Anti-fatigue effect of small molecule oligopeptides from tilapia (Oreochromis Mossambicus) in mice
}

\author{
Shuo PENG ${ }^{1}$ (D), Hongwu JI $I^{1,2,3,4,5 *}$, Wenkui SONG ${ }^{1}$, Liuyi WEI ${ }^{1}$, Suhong $\mathrm{ZHAN}^{1}$, Yushan QU ${ }^{1}$, Ming CHEN ${ }^{1}$, \\ Di ZHANG ${ }^{1}$, Shucheng LIU $^{1,2,3,4,5,6}$
}

\begin{abstract}
In order to promote the development and application of small molecule oligopeptides from tilapia (SMOT), its anti-fatigue effect was evaluated by using exhaustive swimming in mice. The results showed that compared with the negative control group, SMOT could significantly prolong the exhausted swimming time of mice, reduce blood lactic acid, blood urea nitrogen and malondialdehyde content, and could significantly improve liver glycogen storage status. Meanwhile, the activities of superoxide dismutase and glutathione peroxidase of the mice gavaged with SMOT were significantly higher than those in the negative control group. In addition, SMOT could increase the activity of immune factor IL-2, stimulate the secretion of sIgA and regulate the level of inflammatory factors. So SMOT had significant anti-fatigue effect. Its anti-fatigue effect was exerted by increasing energy reserves, eliminating the accumulation of metabolites, reducing oxidative stress, and improving the body's immune function.
\end{abstract}

Keywords: anti-fatigue; oxidative stress; immune regulation; exhaustive swimming in mice; small molecule oligopeptides from tilapia.

Practical Application: It not only promotes the development of the tilapia industry, but also provides a theoretical reference for the development of anti-fatigue dietary supplements.

\section{Introduction}

Fatigue is defined as a feeling of discomfort, and it will lead to inability to complete original normal activities or work under the same conditions. In severe cases, it can even threaten people's physical and mental health (Goncharov et al., 2021). The causes of fatigue often include excessive consumption of energy, massive production and accumulation of metabolites, immune system disorders, oxidative damage, etc. (Li et al., 2020), inflammation and oxidative stress are thought to play an important role in the cause of fatigue (Lee et al., 2015; Ye et al., 2017). With the increasingly fierce competition in modern society, fatigue has become a common social problem (Zhu et al., 2021). Therefore, it is particularly important to relieve fatigue (Li et al., 2017).

For a long time, chemical drugs have been a main treatment to relieve fatigue. However, these drugs have adverse effects on the nervous system and normal physiological activities (Itzhak \& Ali, 2006). In recent years, dietary supplements have attracted much attention (Hu et al., 2020). Peptides have become the focus of research due to their high nutritional value, wide source, fast absorption, and diverse functions (Bo et al., 2021; Chen et al., 2021). Many studies have shown that peptides are safe and effective in reducing fatigue, such as peptides from oysters (Xiao et al., 2020), mackerel (Wang et al., 2014), hairtail (Wang et al., 2020). Aquatic animals are diverse and contain a large number of valuable protein resources, so there is a huge space for development and utilization (Chalamaiah et al., 2019)。

Tilapia (Oreochromis mossambicus) is one of the important farmed freshwater fish in China, but its deep processing industry lags behind and its added value is low (Lin et al., 2021; Shiyan et al., 2021). Therefore, improving its protein utilization rate has attracted widespread attention. So far, there have been more studies on tilapia scraps (Lin et al., 2021). However, its composition is relatively complex, and the content of blood, fat and other impurities is large, which makes the processing process more cumbersome (Huang et al., 2015a). In addition, tilapia scraps are slightly inferior to the sensory quality of tilapia meat (Li et al., 2021),so tilapia meat is a good source of bioactive peptide. At present, studies have reported various biological activities of tilapia protein peptides, such as antioxidant activity (Zhang et al., 2021), angiotensin-converting enzyme inhibitory activity (Toopcham et al., 2017) and calcium-binding activity (Charoenphun et al., 2012), but there are few studies on its anti-fatigue effect. 
To date, there are no in vitro models that can comprehensively and accurately evaluate the degree of anti-fatigue (Wang et al., 2021). Therefore, it is necessary to study the anti-fatigue activity through animal experiments in vivo. In this study, taking mouse swimming as an animal model, the anti-fatigue effect of small molecule oligopeptides from tilapia (SMOT) was discussed by recording the exhausting swimming time of mice, measuring the fatigue related biochemical parameters and immune related parameters, so as to provide reference for the development of high efficacy, low cost, safe and healthy anti-exercise fatigue food.

\section{Materials and methods}

\subsection{Materials}

\section{Materials and reagents}

Fresh tilapia (Oreochromis mossambicus) was purchased from a local market in Zhanjiang, China. After removing scales, head, tail, bones and internal organs of the fish and then cleaning, the fish meat was collected by a meat grinder, and the obtained fish meat was stored in polyethylene bags at $-18{ }^{\circ} \mathrm{C}$ for use.

Papain $\left(2 \times 10^{5} \mathrm{U} / \mathrm{g}\right)$ was purchased from Pangbo Bioengineering Co., Ltd.(Nanning, China); Acetonitrile (HPLC grade) was produced from Sigma, USA; Glutathione was bought from Solarbio Technology Co., Ltd.( Beijing, China); Interleukin-2 (IL-2), interleukin-10(IL-10), interleukin-1 $\beta$ (IL-1 $\beta)$, interferon- $\gamma$ (IFN- $\gamma$ ), tumor necrosis factor-a (TNF-a), secretory immunoglobulin A (sIgA) and Caspase-3(Casp-3) ELISA kit were all obtained from Jiangsu Enzyme Biotechnology Co., Ltd.(Jiangsu, China); Kits for analysis of blood lactic acid (BLD), blood urea nitrogen (BUN), superoxide dismutase (SOD), glutathione peroxidase (GSH-PX), malondialdehyde ( MDA), liver glycogen (LG) were all got from Nanjing Jiancheng Biotechnology Institute (Nanjing, China); All the other chemical reagents were of analytical grade.

\section{Experimental animals}

Ninety KM male mice (SPF, $18 \sim 22$ g) were purchased from Baishitong Biotechnology Co., Ltd. (Certificate No. SYXK (Guangdong) 2019-0204, Zhuhai, China). All animals were provided with standard laboratory feed and water, raised in an SPF laboratory at room temperature $\left(23 \pm 1{ }^{\circ} \mathrm{C}\right)$ and moderate humidity $(45 \% \sim 55 \%)$, with a light-dark cycle for 12 hours. All animal experiments conducted in this study were approved in advance and followed the guidelines of the Ethics Committee of Guangdong Ocean University. The experimental procedures were carried out in strict accordance with the "Guidelines for the Care and Use of Laboratory Animals" of Guangdong Ocean University.

\subsection{Method}

\section{Preparation of SMOT}

Tilapia meat is added distilled water in a ratio of $1: 2$ and homogenized. The homogenate obtained was adjusted to $\mathrm{pH}$
5 , then placed in a constant temperature shaking water bath at $45^{\circ} \mathrm{C}$ to preheat for 10 minutes and enzymatically hydrolyzed with papain of $0.4 \%$ for 4 hours. After the hydrolysis, in order to inactivate the enzyme, the solutions were put in a boiling water bath for $15 \mathrm{~min}$. The hydrolysates were centrifuged at $8000 \mathrm{rpm}, 4^{\circ} \mathrm{C}$ for $15 \mathrm{~min}$, and the supernatant was got after filtered. The samples were separated by the ceramic membrane with a pore size of $200 \mathrm{~nm}$, followed by ultrafiltration membranes with a molecular mass cutoff of $5 \mathrm{kDa}$ and $1 \mathrm{kDa}$ for further separation, and the fractions less than $1 \mathrm{kDa}$ were collected for subsequent experiments.

Determination of the molecular weight distribution and amino acid composition

The molecular weight distribution of SMOT was determined by high performance gel filtration chromatography. The chromatographic conditions were as follows, chromatographic column: TSKgel G2000SWXL $(7.8 \mathrm{~mm} \times 30 \mathrm{~cm})$, mobile phase: acetonitrilewater-trifluoroacetic acid volume ratio of 45:55:0.1, flow rate: $0.5 \mathrm{ml} / \mathrm{min}$, column temperature: $30^{\circ} \mathrm{C}$, detection wavelength: $240 \mathrm{~nm}$. Glycine-glycine-glycine (189.17 Da), glycine-glycinetyrosine-arginine (451.48 Da), L-oxidized glutathione (612.628 Da), bacitracin $(1422.69 \mathrm{Da})$, aprotinin $(6511.51 \mathrm{Da})$ and cytochrome C (12384 Da) were used as standards to make a standard curve of relative molecular mass. The standard curve was obtained by plotting $\lg \mathrm{MW}$ against the retention time. The linear regression equation was: $\mathrm{y}=-4.4732 \mathrm{x}+32.574$.

The amino acid composition of SMOT was determined using a Hitachi LA8080 amino acid auto-analyzer according to the method of GB 5009.124-2016.

\section{Animals and Grouping}

Ninety mice were housed in separate cages, five mice per cage, and after one week of acclimatization, they were randomly divided into six groups: normal control group (CP), negative control group (NC), SMOT low dose group (SMOT-L), SMOT medium dose group (SMOT-M), SMOT high dose group (SMOT-H), and positive control group (PC), in which the normal control and negative control groups were gavaged with distilled water, the low, medium and high dose groups were gavaged with $0.25,0.5$ and $1 \mathrm{mg} / \mathrm{g}$ of SMOT respectively, and the positive control group was gavaged with $0.5 \mathrm{mg} / \mathrm{g}$ of glutathione. Each mouse was gavaged at a dose of $1 \mathrm{~mL} / 100 \mathrm{~g}$. Swimming training was performed after $30 \mathrm{~min}$ of each gavage for $30 \mathrm{~d}$, except for the normal control group, during which the mice were fed and watered freely.

\section{Weight-loaded swimming test}

After the last gavage for 30 minutes, the mice were loaded with $5 \%$ of their body weight in lead skin at the tail and placed in a swimming tank $(61.5 \mathrm{~cm} \times 45.5 \mathrm{~cm} \times 36.5 \mathrm{~cm})$ at a water depth of $30 \mathrm{~cm}$ and a water temperature of $25 \pm 1{ }^{\circ} \mathrm{C}$. The mice were judged to be exhausted when their heads were completely submerged in the water for $7 \mathrm{~s}$ and no longer surfaced. The time taken for the mice to swim to exhaustion was recorded and the mice were quickly retrieved to regain strength. 


\section{Determination of biochemical indicators}

Two days after the weight-loaded swimming test, the mice were placed in a swimming tank $(61.5 \mathrm{~cm} \times 45.5 \mathrm{~cm} \times 36.5 \mathrm{~cm})$ at a water depth of $30 \mathrm{~cm}$ and a water temperature of $25 \pm 1{ }^{\circ} \mathrm{C}$ for $30 \mathrm{~min}$ after gavage administration of the drug for $30 \mathrm{~min}$. At the end of the session, the mice were retrieved and dried off, then placed in the original cage for $30 \mathrm{~min}$ before removing the eyeballs to extract blood and centrifuging the supernatant. The mice were dislocated and executed immediately after blood collection, and the liver, spleen, kidney, proximal jejunum $3 \mathrm{~cm}$ and hind limb gastrocnemius muscle were dissected, rinsed in saline, blotted with filter paper and weighed for subsequent experiments. Serum for LD, BUN, IL-2, IL-10, IL-1 $\beta$, IFN- $\gamma$, TNF-a, liver for hepatic glycogen, gastrocnemius for SOD, GSH-PX, MDA, jejunum for sIgA, Casp-3.

\section{Histopathological observations}

Histological analysis of the gastrocnemius muscle was performed using the method described in a previous study (Botzenhart et al., 2020). Mouse gastrocnemius muscles were dissected and immediately rinsed in saline and then fixed in environmentally friendly GD fixative. The specimens were dehydrated with different gradients of ethanol and embedded in paraffin. The paraffin-embedded specimens were cut transversely into $4 \mu \mathrm{m}$ thick sections, stained with hematoxylin and eosin (HE) and the histomorphology was observed under a NIKON light microscope. After imaging was completed, the Image-Pro Plus 6.0 analysis software was used to count the number of myofibers and measure the total area of myofibers.

\section{Immunohistochemical analysis (IHC)}

The collected gastrocnemius specimens were fixed in environmentally friendly GD fixative and subsequently, the muscle tissue specimens were embedded in paraffin and cut into $4 \mu \mathrm{m}$ thick sections for further analysis. Tissue samples were gradient degreased and rehydrated in xylene and ethanol to remove picric acid. Following antigen repair using microwave oven, the tissue was treated with $30 \% \mathrm{H}_{2} \mathrm{O}_{2}$ for 25 min to block endogenous peroxidase and added 3\% BSA for $30 \mathrm{~min}$ to block non-specific binding. NF- $\kappa \mathrm{B}$ p65 antibody was added and incubated overnight at a humid room temperature of $4{ }^{\circ} \mathrm{C}$. The antigen-antibody complexes were detected using secondary antibodies labelled with horseradish peroxidase, developed in $\mathrm{DAB}$, viewed under a microscope and the mean optical density values of $\mathrm{NF}-\kappa \mathrm{B}$ were measured.

\section{Statistical analysis}

Data were processed using Graphpad prism statistical software, and one-way analysis of variance (One-Way ANOVA) was carried out, with $\mathrm{P}<0.05$ indicating significant differences and $\mathrm{P}<0.01$ indicating highly significant differences. All tests were carried out at least in triplicates and results were expressed as mean \pm standard deviation.

\section{Results and discussion}

\subsection{Molecular weight distribution and amino acid composition of SMOT}

Bioactive peptides are mainly composed of 2-20 amino acids with a wide range of biological activities(Shi et al., 2020) and are well absorbed, well processed and highly active compared to proteins (Yang et al., 2021) . According to the equation, the small molecule peptide in the range of 180-1000 Da accounted for about $96 \%$ of SMOT (Data was not shown in this article). It is therefore tentatively assumed that SMOT have potentially strong bioactivity and high bioavailability.

The biological activity of peptides is not only related to their molecular weight, but also to their amino acid composition (Gao et al., 2021). Previous studies have shown that several amino acids, including Lys, Pro, Met, Tyr, Phe and His, are effective antioxidants (Huang et al., 2015b; You et al., 2012). And hydrophobic amino acids such as Leu, Ala and Val play an important role in scavenging free radicals (Gao et al., 2021). The amino acid composition of SMOT is shown in Table 1. The total content of amino acids accounts for $55.11 \mathrm{~g} / 100 \mathrm{~g}$ and several of the above amino acids reaches $51.24 \%$, suggesting that SMOT may have strong antioxidant activity. Branchedchain amino acids can improve muscle motility during exercise and significantly delay protein catabolism (Wang et al., 2021). The percentage of branched-chain amino acids (Leu, Ile and Val) in this study was $17.96 \%$. Glu is the more abundant amino acid in SMOT (12.28\%) and is also rich in Asp (7.04\%) and Arg (9.40\%). Li et al. (2012) found that black soybean peptides contained $11.02 \%$ Glu and $6.83 \%$ Asp respectively, suggesting that they may have potential anti-fatigue effects. Glu has been found to have a very positive effect on the nervous system and to be helpful during exercise (You et al., 2011) ; Asp is thought to lower blood ammonia concentrations (Xu et al., 2015), thereby delaying the onset of fatigue.

\subsection{Effect of SMOT on body weight and organ index in mice}

The change in body weight of mice during 30 days of administration is shown in Figure 1A, the body weight of mice in each group gradually increased with the extension of time, but there was no significant difference between SMOT groups and NC group, the result indicates that SMOT has no effect on the growth of mice.

Table 1. Amino acid composition of SMOT.

\begin{tabular}{cccc}
\hline Amino acid & Content $(\mathrm{g} / 100 \mathrm{~g})$ & Amino acid & Content $(\mathrm{g} / 100 \mathrm{~g})$ \\
\hline Asp & 3.88 & Met & 1.62 \\
Thr & 2.38 & Ile & 1.92 \\
Ser & 2.25 & Leu & 4.77 \\
Glu & 6.77 & Tyr & 1.49 \\
Pro & 1.93 & Phe & 2.09 \\
Gly & 4.49 & Lys & 7.00 \\
Ala & 4.10 & His & 2.03 \\
Val & 3.21 & Arg & 5.18 \\
\hline
\end{tabular}



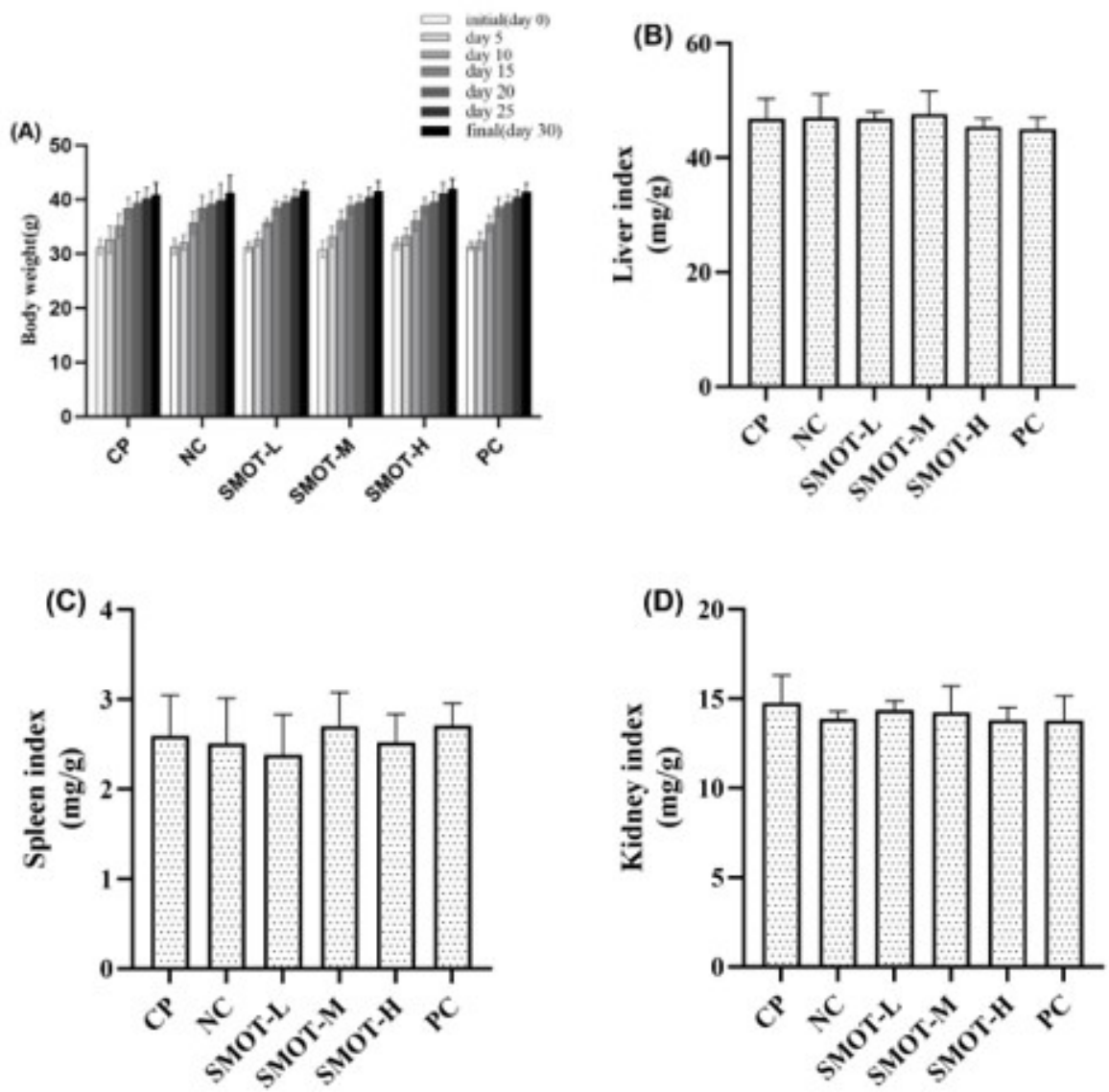

Figure 1. The effect of SMOT on the body weight and the organ index of mice: (A) The change in body weight; (B) The liver index; (C) The spleen index; (D) The kidney index. (Compared with $\mathrm{CP}, \# \mathrm{P}<0.05$, \#\# $<0.01$; Compared with $\mathrm{NC},{ }^{\star} \mathrm{P}<0.05$, ${ }^{*} \mathrm{P}<0.01$ ).

The liver is an important metabolic and detoxifying organ in the body. The spleen is the largest lymphatic organ in the body(Liu et al., 2020). As can be seen from Figure 1BCD, SMOT groups showed an increasing in organ index compared with the NC group, suggesting that SMOT can improve immunity in mice to some extent. However, there was no significant difference between the groups, indicating that SMOT have no toxic side effects and are safe and usable.

\subsection{In vivo anti-fatigue activity of SMOT}

As one of the key indicators for the evaluation of anti-fatigue efficacy, the exhaustion swimming time can visually reflect the exercise capacity of the animal (Ma et al., 2017). The mice's exhaustive swimming time is shown in Figure 2A. The mice in SMOT group all had higher swimming time than the NC group, but there was no dose-dependent relationship. Similar results were seen in the study by Wang et al.(2020). There were highly significant differences between the SMOT-M, SMOT-H groups and the NC group, which were 2.07 and 1.51 times that of the NC group, respectively, indicating that SMOT could improve the locomotor ability and prolong the exhaustive swimming time in mice.

During strenuous exercise, the body's oxygen consumption increases and anaerobic enzymatic reactions are accelerated, resulting in the production of large amounts of lactic acid. The accumulation of excess lactic acid lowers the $\mathrm{pH}$ of the internal environment, causing muscle soreness and reducing exercise capacity, which leads to fatigue (Guo et al., 2017; Wang et al., 2008). As shown in Figure 2B, there was a tendency for the lactate content to increase after exercise, but it was not statistically significant. Compared with NC group, the lactate content in SMOT were all significantly reduced, and the SMOT-L, SMOT-M and SMOT-H groups were reduced by $15.34 \%, 19.50 \%$ and $16.87 \%$ respectively. The results indicated that SMOT could effectively reduce the production of lactate.

Under normal physiological conditions, urea production and excretion are in dynamic equilibrium. During exercise, the balance of energy metabolism in muscle is disrupted and the body is unable to obtain sufficient energy from the catabolism of sugar; Proteins and amino acids, therefore, have a higher catabolic rate which leads to an increase in urea production (Chen et al., 2020) . Thus BUN is also often used as one of the important indicators to determine the degree of fatigue (Ding et al., 2011). Figure 2C shows that there is a tendency for BUN levels to increase significantly after exercise, and SMOT significantly mitigate this tendency.

As exercise progresses, glycogen is depleted and blood glucose levels will be difficult to maintain, which then causes 
hypoglycemia that can inhibit brain function and result in the inability to continue exercising. When glycogen is depleted in large amounts, the body's endurance decreases significantly (Miao et al., 2018). Therefore, glycogen level is a sensitive indicator in relation to fatigue. As shown in Figure 2D, the liver glycogen content of mice in the SMOT-M group increased significantly by $28.66 \%$ compared to the NC group, while the other two groups fed with SMOT showed an increasing trend in liver glycogen content, but not significantly. These results suggest that SMOT may improve physical endurance by increasing glycogen reserves or reducing glycogen depletion or both.

\subsection{Antioxidant activity of SMOT}

Strenuous exercise will break the balance between oxidative and antioxidant systems and produce excessive reactive oxygen species, which react with unsaturated fatty acids, leading to lipid peroxidation (Cai et al., 2021; Xu et al., 2018). Skeletal muscle, a powerful metabolic tissue in the human body, is the lipid peroxidation tissue most affected by strenuous exercise (Shen et al., 2021). MDA is one of the products of lipid peroxidation, reflecting the degree of oxidative stress in body tissues and cells. SOD is an important antioxidant enzyme in humans and GSH-PX is an important lipid peroxidase decomposing enzyme in the body, which can effectively scavenge the reactive oxygen species and protect the organism from oxidative damage (Jiang et al., 2018; Wang et al., 2020; Zhao et al., 2021). As shown in Figure 3, SMOT significantly increased SOD and GSH-PX activity and decreased MDA content, indicating that SMOT can alleviate the degree of lipid peroxidation, increase the activity of antioxidant enzymes and maintain the balance between the oxidative and antioxidant systems of the body, thus it is hypothesized that tilapia peptides may be able to delay the production of fatigue by reducing oxidative damage.

\subsection{Effect of SMOT on muscle tissue}

Skeletal muscle has an important role in the body's metabolism and exercise endurance, and morphological features such as muscle fiber cross-sections are important indicators of the health and function of the skeletal muscle system (Shen et al., 2021). High-intensity exercise leads to the production of large amounts of reactive oxygen species, which causes losses to muscle tissue, resulting in a reduction in muscle mass and muscle fiber area (Yin et al., 2021). The effect of SMOT on mouse gastrocnemius muscle is shown in Figure 4, the morphology of muscle fibers in NC group was
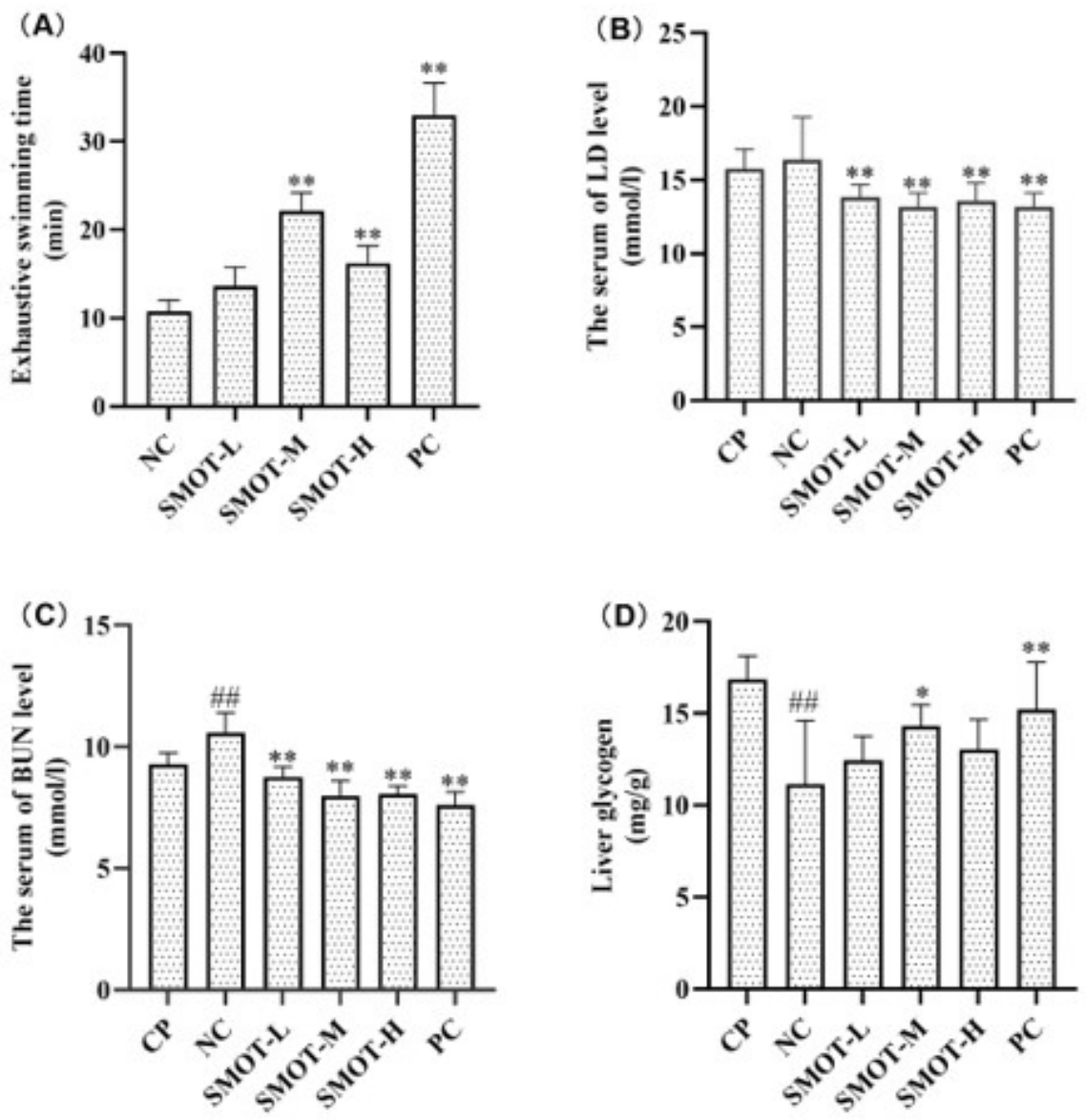

Figure 2. The effect of SMOT on the fatigue-related biochemical indicators of mice: (A) The exhausted swimming time; (B) The content of lactic acid; (C) The content of urea nitrogen; (D) The content of liver glycogen (Compared with $\mathrm{CP}, \# \mathrm{P}<0.05$, \#\# $<<0.01$; Compared with $\mathrm{NC}$, ${ }^{\star} \mathrm{P}<$ $\left.0.05,{ }^{* *} \mathrm{P}<0.01\right)$. 

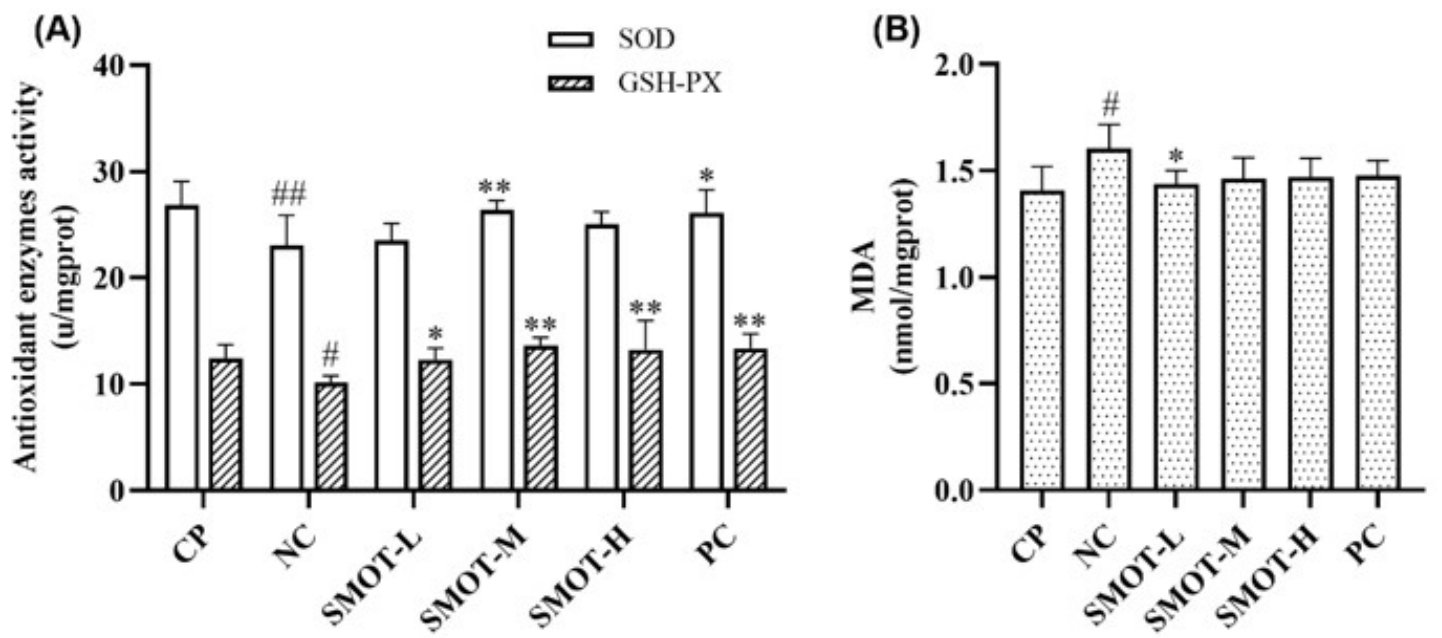

Figure 3. The effect of SMOT on SOD, GSH-PX and MDA in mice (Compared with CP, $\# \mathrm{P}<0.05, \# \# \mathrm{P}<0.01$; Compared with $\mathrm{NC}$, ${ }^{\star} \mathrm{P}<0.05$, ${ }^{\star *} \mathrm{P}<0.01$ ).
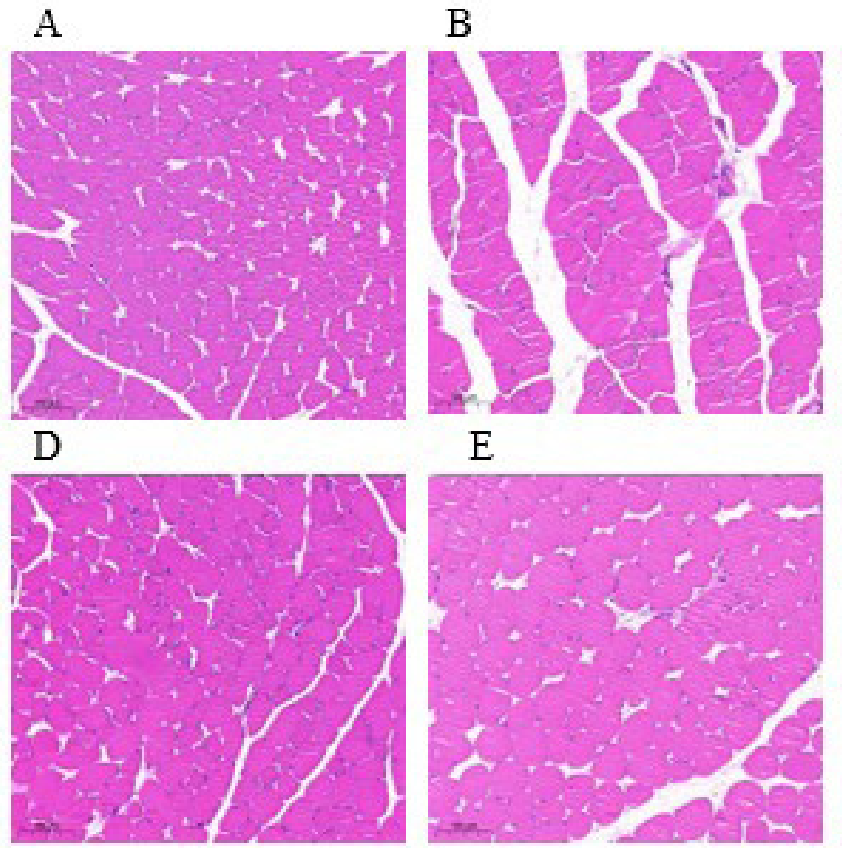

B

E
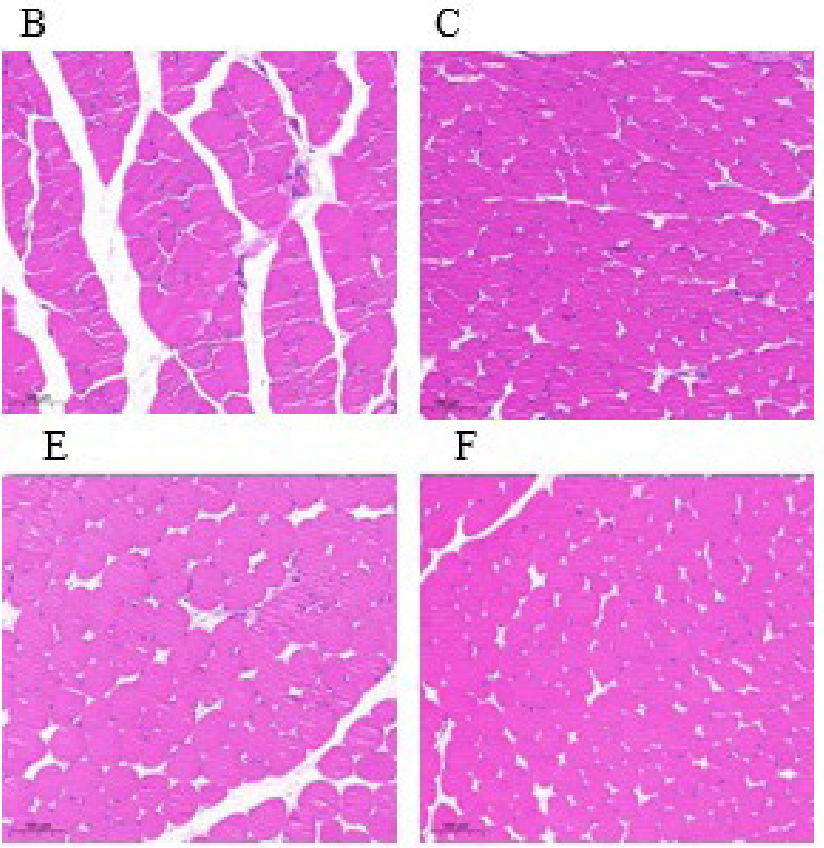

F

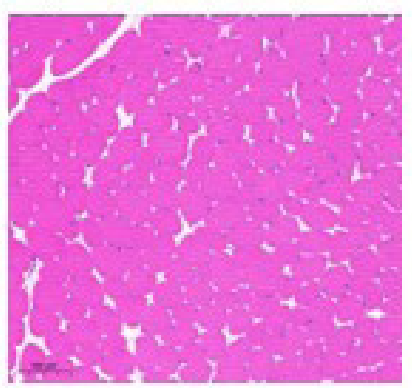

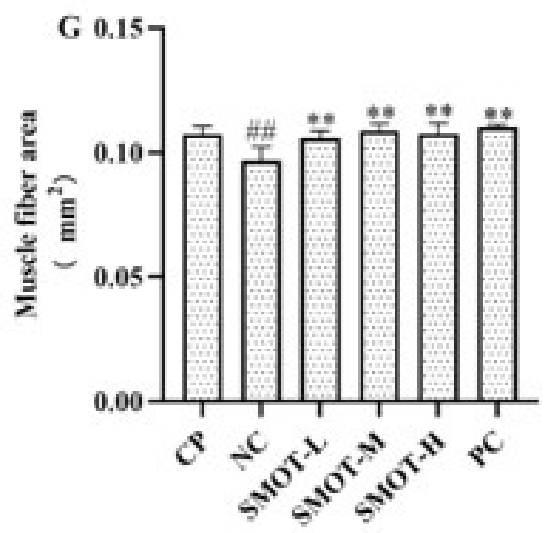

Figure 4. The effect of SMOT on mouse gastrocnemius muscle. A: Normal control group (CP); B: Negative control group (NC); C: SMOT lowdose group (SMOT-L); D: SMOT medium-dose group (SMOT-M); E: SMOT high-dose group (SMOT-H); F: Positive control group (PC); G: Muscle fiber area. (Compared with $\mathrm{CP}, \# \mathrm{P}<0.05, \# \# \mathrm{P}<0.01$; Compared with $\mathrm{NC},{ }^{\star} \mathrm{P}<0.05,{ }^{* *} \mathrm{P}<0.01$ ). 
variable. The muscle fibers were obviously atrophied, loosely arranged and had more intracellular cracks (Figure 4B), while the muscle fibers in SMOT group were tightly arranged with slight cracks (Figure 4CDE). The protective effect of SMOT on gastrocnemius muscle is consistent with the fact that SMOT can increase SOD and GSH-PX activity and reduce oxidative damage, and Zheng et al. (2019) reported that macamides extract can alleviate fatigue by reducing muscle damage in mice. From Figure 4G, it can be seen that SMOT significantly increased the area of muscle fibers in mice, which was caused by the thickening of muscle fibers. The thickening of muscle fibers indicates that there is more energy material in muscle fibers and more myoglobulin content, which improves the quality of muscle fibers and greatly increases the force of muscle fibers (Mizunoe et al., 2021; Wen et al., 2021). From the above, it can be seen that SMOT has an improvement effect on muscle quality and strength, which can improve the exercise ability of mice. In contrast, the SMOT group showed a significant increase in exhaustion swimming time.

\subsection{Effect of SMOT on immune function}

High-intensity exercise causes a series of physiological and biochemical changes in the muscles, intestines, blood and nervous system, leading to fatigue and reduced immunity. (Anderson \& Maes, 2020). In this study, preliminary studies on the immunomodulatory effects of SMOT were carried out using interleukins (IL-1 $\beta$, IL-2 and IL-10), TNF-a, IFN- $\gamma$, Casp- 3 and sIgA. TNF- $\alpha$ is the earliest and most important inflammatory mediator during the inflammatory response, regulates other tissue metabolic activities and contributes to the synthesis and release of other cytokines. IL- $1 \beta$ is an isoform of IL- 1 that promotes the release of TNF- $\alpha$. TNF- $\alpha$ and IL- $1 \beta$ are considered to be pro-inflammatory factors (Ge et al., 2021).
IFN- $\gamma$ and IL- 2 are factors with broad immunomodulatory effects. And IL-10 inhibits the synthesis and release of inflammatory factors (Nam et al., 2016) . In Table 2, TNF- $a$ and IL-1 $\beta$ levels were significantly increased after exercise, and SMOT significantly reduced the levels of these factors. IL10 levels were significantly up-regulated after SMOT treatment. These results suggest that SMOT may delay the production of fatigue by regulating inflammatory factors. IL-2 levels were significantly increased in the SMOT group, while IFN- $\gamma$ did not change significantly, suggesting that SMOT may have a potential immunomodulatory effect.

Caspase-3 is the main terminal shear enzyme in apoptosis and plays an irreplaceable role in apoptosis (Zheng et al., 2017) . sIgA, as the main antibody in mucosal immunity, is responsible for an important immune function (Feng et al., 2021). From Table 2 we can find that the sIgA concentration in mice in the SMOT group was extremely significantly higher than that in the NC group, while there was no significant difference in Caspase- 3 between the groups.

\subsection{IHC detection of NF- $\kappa B$ expression in muscle tissue}

$\mathrm{NF}-\kappa \mathrm{B}$, an important transcription factor involved in the regulation of the immune response, is normally present in the cytoplasm as a homo- or heterodimeric inactive form. Once NF- $\kappa B$ dimers are activated, NF- $\kappa B$ is released and translocated to the nucleus(Yuan et al., 2021), triggering gene expression of pro-inflammatory mediators. NF- $\mathrm{kB}$ expression levels was shown in Figure 5. The expression of NF- $\mathrm{KB}$ factor was stimulated after exercise (Figure 5B), while the SMOT group inhibited the expression of this factor, from which it can be speculated that SMOT may alleviate the production of fatigue through anti-inflammation.

Table 2. Immune related parameters.

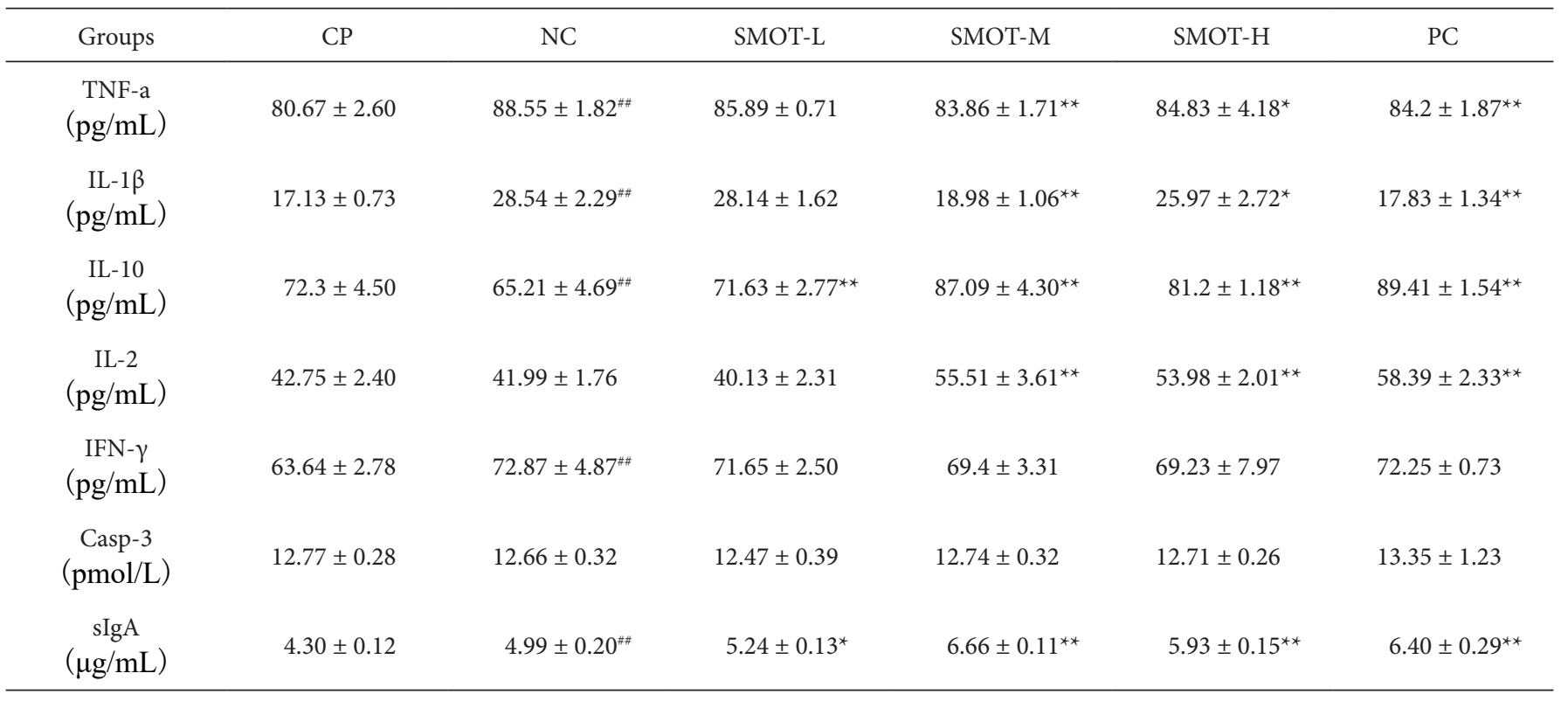

Compared with $\mathrm{CP}, \# \mathrm{P}<0.05$, \# $\mathrm{P}<0.01$; Compared with $\mathrm{NC}$. ${ }^{*} \mathrm{P}<0.05$. ${ }^{*} \mathrm{P}<0.01$. 
A

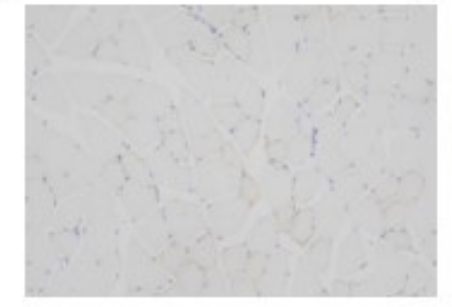

D

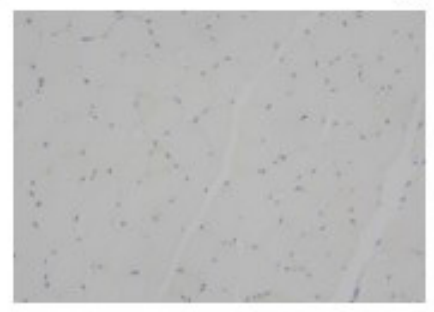

B

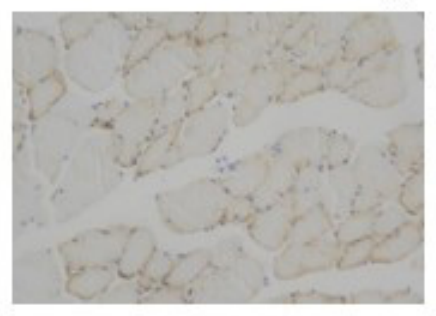

F
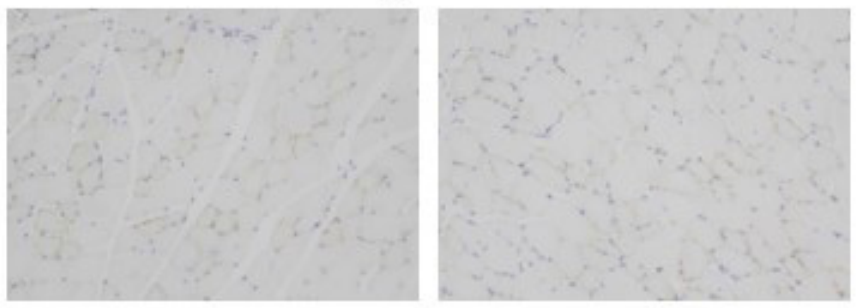

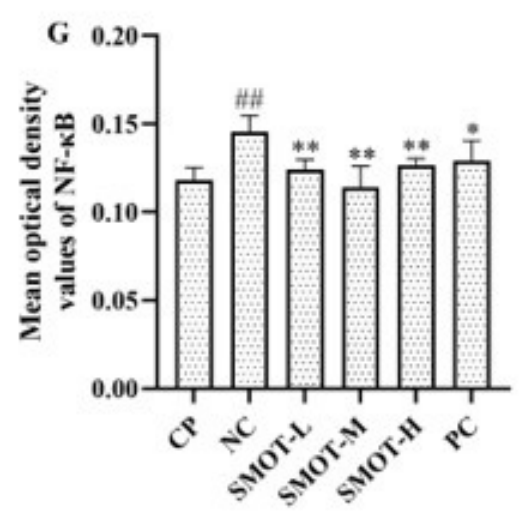

Figure 5. The effect of SMOT on mouse gastrocnemius NF- $\kappa$ B. A: Normal control group (CP); B: Negative control group (NC); C: SMOT lowdose group (SMOT-L); D: SMOT medium-dose group (SMOT-M); E: SMOT high-dose group (SMOT-H); F: Positive control group (PC); G: Mean optical density values of NF- $\kappa$ B. Compared with $\mathrm{CP}, \# \mathrm{P}<0.05, \# \# \mathrm{P}<0.01$; Compared with $\mathrm{NC},{ }^{\star} \mathrm{P}<0.05,{ }^{*} \mathrm{P}<0.01$.

\section{Conclusion}

In this study, significant anti-fatigue effect of small molecule oligopeptides from tilapia has been confirmed by exhaustive swimming in mice. Its anti-fatigue effect was exerted by increasing energy reserves, eliminating the accumulation of metabolites, reducing oxidative stress, and improving the body's immune function. This finding suggested that SMOT could be a promising nutraceutical supplementation for improving exercise performance and relieving physical fatigue.

\section{Funding}

This work was supported by the National Key Research and Development Program (2019YFD0902004).

\section{References}

Anderson, G., \& Maes, M. (2020). Mitochondria and immunity in chronic fatigue syndrome. Progress in Neuro-Psychopharmacology \& Biological Psychiatry, 103, 109976. http://dx.doi.org/10.1016/j. pnpbp.2020.109976. PMid:32470498.
Bo, W., Chen, L., Qin, D., Geng, S., Li, J., Mei, H., Li, B., \& Liang, G. (2021). Application of quantitative structure-activity relationship to food-derived peptides: methods, situations, challenges and prospects. Trends in Food Science \& Technology, 114, 176-188. http://dx.doi. org/10.1016/j.tifs.2021.05.031.

Botzenhart, U. U., Gredes, T., Gerlach, R., Zeidler-Rentzsch, I., Gedrange, T., \& Keil, C. (2020). Histological features of masticatory muscles after botulinum toxin A injection into the right masseter muscle of dystrophin deficient (mdx-) mice. Annals of Anatomy, 229, 151464. http://dx.doi.org/10.1016/j.aanat.2020.151464. PMid:31978572.

Cai, M., Xing, H., Tian, B., Xu, J., Li, Z., Zhu, H., Yang, K., \& Sun, P. (2021). Characteristics and antifatigue activity of graded polysaccharides from Ganoderma lucidum separated by cascade membrane technology. Carbohydrate Polymers, 269, 118329. http://dx.doi.org/10.1016/j. carbpol.2021.118329. PMid:34294340.

Chalamaiah, M., Ulug, S. K., Hong, H., \& Wu, J. (2019). Regulatory requirements of bioactive peptides (protein hydrolysates) from food proteins. Journal of Functional Foods, 58, 123-129. http://dx.doi. org/10.1016/j.jff.2019.04.050.

Charoenphun, N., Cheirsilp, B., Sirinupong, N., \& Youravong, W. (2012). Calcium-binding peptides derived from tilapia (Oreochromis niloticus) protein hydrolysate. European Food Research and Technology, 236(1), 57-63. http://dx.doi.org/10.1007/s00217-012-1860-2. 
Chen, D., Shu, Y., Chen, J., \& Cao, X. (2021). Preparation and in vitro bioactive evaluation of cashew-nut proteins hydrolysate as a potential source of anti-allergy peptides. Journal of Food Science and Technology, 58(10), 3780-3789. http://dx.doi.org/10.1007/s13197020-04838-z. PMid:34471301.

Chen, Y., Wang, F., Zhou, J., Niu, T., Xuan, R., Chen, H., \& Wu, W. (2020). In vivo antifatigue activity of spirulina peptides achieved by their antioxidant activity and by acting on fat metabolism pathway in mice. Natural Product Communications, 15(8), 1-11.

Ding, J. F., Li, Y. Y., Xu, J. J., Su, X. R., Gao, X., \& Yue, F. P. (2011). Study on effect of jellyfish collagen hydrolysate on anti-fatigue and anti-oxidation. Food Hydrocolloids, 25(5), 1350-1353. http://dx.doi. org/10.1016/j.foodhyd.2010.12.013.

Feng, T., Huang, Y., Tang, Z., Wei, D., \& Mo, J. (2021). Anti-fatigue effects of pea (Pisum sativum L.) peptides prepared by compound protease. Journal of Food Science and Technology, 58(6), 2265-2272. http://dx.doi.org/10.1007/s13197-020-04737-3. PMid:33967323.

Gao, R., Yu, Q., Shen, Y., Chu, Q., Chen, G., Fen, S., Yang, M., Yuan, L., McClements, D. J., \& Sun, Q. (2021). Production, bioactive properties, and potential applications of fish protein hydrolysates: developments and challenges. Trends in Food Science \& Technology, 110, 687-699. http://dx.doi.org/10.1016/j.tifs.2021.02.031.

Ge, H., Cai, Z., Chai, J., Liu, J., Liu, B., Yu, Y., Liu, J., \& Zhang, T. (2021). Egg white peptides ameliorate dextran sulfate sodiuminduced acute colitis symptoms by inhibiting the production of pro-inflammatory cytokines and modulation of gut microbiota composition. Food Chemistry, 360, 129981. http://dx.doi.org/10.1016/j. foodchem.2021.129981. PMid:34020366.

Goncharov, N. V., Korf, E. A., Novozhilov, A. V., Jenkins, R. O., \& Avdonin, P. V. (2021). Nutraceuticals in sports activities and fatigue. In R. C. Gupta, R. Lall \& A. Srivastava (Eds.), Nutraceuticals (Chapter 15, 2nd ed., pp. 215-228). United States: Academic Press. http://dx.doi. org/10.1016/B978-0-12-821038-3.00015-X.

Guo, Z., Lin, D., Guo, J., Zhang, Y., \& Zheng, B. (2017). In vitro antioxidant activity and in vivo anti-fatigue effect of sea horse (Hippocampus) peptides. Molecules, 22(3), 482. http://dx.doi. org/10.3390/molecules22030482. PMid:28335458.

Hu, M., Du, J., Du, L., Luo, Q., \& Xiong, J. (2020). Anti-fatigue activity of purified anthocyanins prepared from purple passion fruit (P. edulis Sim) epicarp in mice. Journal of Functional Foods, 65, 103725. http://dx.doi.org/10.1016/j.jff.2019.103725.

Huang, B. B., Lin, H. C., \& Chang, Y. W. (2015a). Analysis of proteins and potential bioactive peptides from tilapia (Oreochromis spp.) processing co-products using proteomic techniques coupled with BIOPEP database. Journal of Functional Foods, 19, 629-640. http:// dx.doi.org/10.1016/j.jff.2015.09.065.

Huang, S., Lin, H., \& Deng, S. G. (2015b). Study of anti-fatigue effect in rats of ferrous chelates including hairtail protein hydrolysates. Nutrients, 7(12), 9860-9871. http://dx.doi.org/10.3390/nu7125504. PMid:26633476.

Itzhak, Y., \& Ali, S. F. (2006). Role of nitrergic system in behavioral and neurotoxic effects of amphetamine analogs. Pharmacology \& Therapeutics, 109(1-2), 246-262. http://dx.doi.org/10.1016/j. pharmthera.2005.08.004. PMid:16154200.

Jiang, X., Chu, Q., Li, L., Qin, L., Hao, J., Kou, L., Lin, F., \& Wang, D. (2018). The anti-fatigue activities of Tuber melanosporum in a mouse model. Experimental and Therapeutic Medicine, 15(3), 3066-3073. http://dx.doi.org/10.3892/etm.2018.5793. PMid:29599841.

Lee, J. S., Kim, H. G., Han, J. M., Kim, Y. A., \& Son, C. G. (2015). Antifatigue effect of Myelophil in a chronic forced exercise mouse model.
European Journal of Pharmacology, 764, 100-108. http://dx.doi. org/10.1016/j.ejphar.2015.06.055. PMid:26142828.

Li, H., Liu, E. Q., Wu, Y. H., \& Chen, S. L. (2012). The anti-fatigue effect of black soybean peptide in mice. In S. Chen, Z. T. Liu \& Q. Zeng (Eds.), Advanced materials research (Vol. 554-556, pp. 1475-1482). Switzerland: Trans Tech Publications.

Li, J., Sun, Q., Meng, Q., Wang, L., Xiong, W., \& Zhang, L. (2017). Antifatigue activity of polysaccharide fractions from Lepidium meyenii Walp. (maca). International Journal of Biological Macromolecules, 95, 1305-1311. http://dx.doi.org/10.1016/j.ijbiomac.2016.11.031. PMid:27840217.

Li, R., Sun, Z., Zhao, Y., Li, L., Yang, X., Cen, J., Chen, S., Li, C., \& Wang, Y. (2021). Application of UHPLC-Q-TOF-MS/MS metabolomics approach to investigate the taste and nutrition changes in tilapia fillets treated with different thermal processing methods. Food Chemistry, 356, 129737. http://dx.doi.org/10.1016/j.foodchem.2021.129737. PMid:33836358.

Li, W., Luo, C., Huang, Y., Zhan, J., Lei, J., Li, N., Huang, X., \& Luo, H. (2020). Evaluation of antifatigue and antioxidant activities of the marine microalgae Isochrysis galbana in mice. Food Science and Biotechnology, 29(4), 549-557. http://dx.doi.org/10.1007/s10068019-00694-6. PMid:32296566.

Lin, S., Hu, X., Li, L., Yang, X., Chen, S., Wu, Y., \& Yang, S. (2021). Preparation, purification and identification of iron-chelating peptides derived from tilapia (Oreochromis niloticus) skin collagen and characterization of the peptide-iron complexes. Lwt, 149, 111796. http://dx.doi.org/10.1016/j.lwt.2021.111796.

Liu, Y., Li, D., Wei, Y., Ma, Y., Wang, Y., Huang, L., \& Wang, Y. (2020). Hydrolyzed peptides from purple perilla (Perilla frutescens L. Britt.) seeds improve muscle synthesis and exercise performance in mice. Journal of Food Biochemistry, 44(11), e13461. http://dx.doi. org/10.1111/jfbc.13461. PMid:32984958.

Ma, G. D., Chiu, C. H., Hsu, Y. J., Hou, C. W., Chen, Y. M., \& Huang, C. C. (2017). Changbai mountain ginseng (Panax ginseng C.A. Mey) extract supplementation improves exercise performance and energy utilization and decreases fatigue-associated parameters in mice. Molecules, 22(2), 237. http://dx.doi.org/10.3390/molecules22020237. PMid:28165424.

Miao, J., Liao, W., Kang, M., Jia, Y., Wang, Q., Duan, S., Xiao, S., Cao, Y., \& Ji, H. (2018). Anti-fatigue and anti-oxidant activities of oyster (Ostrea rivularis) hydrolysate prepared by compound protease. Food \& Function, 9(12), 6577-6585. http://dx.doi.org/10.1039/ C8FO01879K. PMid:30488053.

Mizunoe, Y., Kobayashi, M., Saito, H., Goto, A., Migitaka, R., Miura, K., Okita, N., Sudo, Y., Tagawa, R., Yoshida, M., Umemori, A., Nakagawa, Y., Shimano, H., \& Higami, Y. (2021). Prolonged caloric restriction ameliorates age-related atrophy in slow and fast muscle fibers of rat soleus muscle. Experimental Gerontology, 154, 111519. http://dx.doi.org/10.1016/j.exger.2021.111519. PMid:34416335.

Nam, S. Y., Kim, H. M., \& Jeong, H. J. (2016). Anti-fatigue effect by active dipeptides of fermented porcine placenta through inhibiting the inflammatory and oxidative reactions. Biomedicine and Pharmacotherapy, 84, 51-59. http://dx.doi.org/10.1016/j. biopha.2016.09.012. PMid:27636512.

Shen, W. D., Li, X. Y., Deng, Y. Y., Zha, X. Q., Pan, L. H., Li, Q. M., \& Luo, J. P. (2021). Polygonatum cyrtonema Hua polysaccharide exhibits anti-fatigue activity via regulating osteocalcin signaling. International Journal of Biological Macromolecules, 175, 235-241. http://dx.doi.org/10.1016/j.ijbiomac.2021.01.200. PMid:33548311.

Shi, J., Su, R. Q., Zhang, W. T., \& Chen, J. (2020). Purification and the secondary structure of a novel angiotensin I-converting enzyme 
(ACE) inhibitory peptide from the alcalase hydrolysate of seahorse protein. Journal of Food Science and Technology, 57(11), 3927-3934. http://dx.doi.org/10.1007/s13197-020-04427-0. PMid:33071314.

Shiyan, R., Liping, S., Xiaodong, S., Jinlun, H., \& Yongliang, Z. (2021). Novel umami peptides from tilapia lower jaw and molecular docking to the taste receptor T1R1/T1R3. Food Chemistry, 362, 130249. http://dx.doi.org/10.1016/j.foodchem.2021.130249. PMid:34111693.

Toopcham, T., Mes, J. J., Wichers, H. J., Roytrakul, S., \& Yongsawatdigul, J. (2017). Bioavailability of angiotensin I-converting enzyme (ACE) inhibitory peptides derived from Virgibacillus halodenitrificans SK13-7 proteinases hydrolyzed tilapia muscle proteins. Food Chemistry, 220, 190-197. http://dx.doi.org/10.1016/j.foodchem.2016.09.183. PMid:27855889.

Wang, L., Zhang, H. L., Lu, R., Zhou, Y. J., Ma, R., Lv, J. Q., Li, X. L., Chen, L. J., \& Yao, Z. (2008). The decapeptide CMS001 enhances swimming endurance in mice. Peptides, 29(7), 1176-1182. http:// dx.doi.org/10.1016/j.peptides.2008.03.004. PMid:18440669.

Wang, P., Wang, D., Hu, J., Tan, B. K., Zhang, Y., \& Lin, S. (2021). Natural bioactive peptides to beat exercise-induced fatigue: a review. Food Bioscience, 43, 101298. http://dx.doi.org/10.1016/j.fbio.2021.101298.

Wang, P., Zeng, H., Lin, S., Zhang, Z., Zhang, Y., \& Hu, J. (2020). Antifatigue activities of hairtail (Trichiurus lepturus) hydrolysate in an endurance swimming mice model. Journal of Functional Foods, 74, 104207. http://dx.doi.org/10.1016/j.jff.2020.104207.

Wang, X., Xing, R., Chen, Z., Yu, H., Li, R., \& Li, P. (2014). Effect and mechanism of mackerel (Pneumatophorus japonicus) peptides for anti-fatigue. Food \& Function, 5(9), 2113-2119. http://dx.doi. org/10.1039/C4FO00121D. PMid:25002163.

Wen, W., Chen, X., Huang, Z., Chen, D., Yu, B., He, J., Zheng, P., Luo, Y., Yan, H., \& Yu, J. (2021). Lycopene increases the proportion of slow-twitch muscle fiber by AMPK signaling to improve muscle antifatigue ability. The Journal of Nutritional Biochemistry, 94, 108750. http://dx.doi.org/10.1016/j.jnutbio.2021.108750. PMid:33933581.

Xiao, M., Lin, L., Chen, H., Ge, X., Huang, Y., Zheng, Z., Li, S., Pan, Y., Liu, B., \& Zeng, F. (2020). Anti-fatigue property of the oyster polypeptide fraction and its effect on gut microbiota in mice. Food \& Function, 11(10), 8659-8669. http://dx.doi.org/10.1039/ D0FO01713B. PMid:32936195.

Xu, J., Zhao, Q., Qu, Y., \& Ye, F. (2015). Antioxidant activity and antiexercise-fatigue effect of highly denatured soybean meal hydrolysate prepared using neutrase. Journal of Food Science and Technology, 52(4), 1982-1992. http://dx.doi.org/10.1007/s13197-013-1220-7. PMid:25829578.

Xu, X., Ding, Y., Yang, Y., Gao, Y., Sun, Q., Liu, J., Yang, X., Wang, J., \& Zhang, J. (2018). Beta-glucan salecan improves exercise performance and displays anti-fatigue effects through regulating energy metabolism and oxidative stress in mice. Nutrients, 10(7), 858. http://dx.doi. org/10.3390/nu10070858. PMid:29970808.
Yang, F., Chen, X., Huang, M., Yang, Q., Cai, X., Chen, X., Du, M., Huang, J., \& Wang, S. (2021). Molecular characteristics and structureactivity relationships of food-derived bioactive peptides. Journal of Integrative Agriculture, 20(9), 2313-2332. http://dx.doi.org/10.1016/ s2095-3119(20)63463-3.

Ye, J., Shen, C., Huang, Y., Zhang, X., \& Xiao, M. (2017). Anti-fatigue activity of sea cucumber peptides prepared from Stichopus japonicus in an endurance swimming rat model. Journal of the Science of Food and Agriculture, 97(13), 4548-4556. http://dx.doi.org/10.1002/ jsfa.8322. PMid:28337772.

Yin, L., Li, N., Jia, W., Wang, N., Liang, M., Yang, X., \& Du, G. (2021). Skeletal muscle atrophy: from mechanisms to treatments. Pharmacological Research, 172, 105807. http://dx.doi.org/10.1016/j. phrs.2021.105807. PMid:34389456.

You, L., Ren, J., Yang, B., Regenstein, J., \& Zhao, M. (2012). Antifatigue activities of loach protein hydrolysates with different antioxidant activities. Journal of Agricultural and Food Chemistry, 60(50), 12324-12331. http://dx.doi.org/10.1021/jf3037825. PMid:23136870.

You, L., Zhao, M., Regenstein, J. M., \& Ren, J. (2011). In vitro antioxidant activity and in vivo anti-fatigue effect of loach (Misgurnus anguillicaudatus) peptides prepared by papain digestion. Food Chemistry, 124(1), 188-194. http://dx.doi.org/10.1016/j.foodchem.2010.06.007.

Yuan, L., Zhang, L., Yao, N., Wu, L., Liu, J., Liu, F., Zhang, H., Hu, X., Xiong, Y., \& Xia, C. (2021). Upregulation of UGT1A1 expression by ursolic acid and oleanolic acid via the inhibition of the $\mathrm{PKC/}$ NF- $\mathrm{BB}$ signaling pathway. Phytomedicine, 92, 153726. http://dx.doi. org/10.1016/j.phymed.2021.153726. PMid:34536821.

Zhang, X., Noisa, P., \& Yongsawatdigul, J. (2021). Identification and characterization of tilapia antioxidant peptides that protect AAPHinduced HepG2 cell oxidative stress. Journal of Functional Foods, 86, 104662. http://dx.doi.org/10.1016/j.jff.2021.104662.

Zhao, W., Zhang, W., Liu, L., Cheng, Y., Guo, Y., Yao, W., \& Qian, H. (2021). Fractionation, characterization and anti-fatigue activity of polysaccharides from Brassica rapa L. Process Biochemistry, 106, 163-175. http://dx.doi.org/10.1016/j.procbio.2021.04.016.

Zheng, Y., Zhang, W. C., Wu, Z. Y., Fu, C. X., Hui, A. L., Gao, H., Chen, P. P., Du, B., \& Zhang, H. W. (2019). Two macamide extracts relieve physical fatigue by attenuating muscle damage in mice. Journal of the Science of Food and Agriculture, 99(3), 1405-1412. http://dx.doi. org/10.1002/jsfa.9318. PMid:30120787.

Zheng, Z., Yang, X., Liu, J., Qian, P., Hao, L., Wang, Z., \& Guo, S. (2017). Effects of wheat peptide supplementation on anti-fatigue and immunoregulation during incremental swimming exercise in rats. RSC Advances, 7(69), 43345-43355. http://dx.doi.org/10.1039/ C7RA07860A.

Zhu, J., Yi, J., Kang, Q., Huang, J., Cui, Y., Zhang, G., Wang, Z., Zhang, L., Zheng, Z., Lu, J., \& Hao, L. (2021). Anti-fatigue activity of hemp leaves water extract and the related biochemical changes in mice. Food and Chemical Toxicology, 150, 112054. http://dx.doi.org/10.1016/j. fct.2021.112054. PMid:33577943. 